\title{
Theoretical Analysis on the Micro Gas Turbine Integrated Solar Farm for Power Output Stabilization
}

\author{
Firdaus Basrawi ${ }^{1,}{ }^{*}$, A.I.M. Al-Anati ${ }^{1}$, Thamir K. Ibrahim ${ }^{1,2}$ Mohd Hazwan Yusof $^{1}$, A. A. \\ Razak $^{3}$, Shaharin Anuar Sulaiman ${ }^{4}$ and Takanobu Yamada ${ }^{5}$ \\ ${ }^{1}$ Energy Sustainability Focus Group (ESFG), Faculty of Mechanical Engineering, Universiti \\ Malaysia Pahang, 26600 Pekan, Pahang, Malaysia. \\ ${ }^{2}$ Department of Mechanical Engineering, College of Applied Engineering, University of Tikrit, Tikrit, \\ Iraq \\ ${ }^{3}$ Faculty of Engineering Technology, Universiti Malaysia Pahang, Lebuhraya Tun Razak, 26300 \\ Gambang, Pahang, Malaysia. \\ ${ }^{4}$ Department of Mechanical Engineering, Universiti Teknologi PETRONAS, 32610 Seri Iskandar, \\ Malaysia \\ ${ }^{5}$ Department of Mechanical Engineering, Kitami Institute of Technology, 165, Koen-Cho, Kitami \\ City, Hokkaido 090-8507, Japan
}

\begin{abstract}
Solar farm could not penetrate grid at substantial amount because it could disturb the grid operation due to its fluctuation output. This, the objective of this study is to theoretically analyze the power output stabilization of a solar farm by integration of Micro Gas Turbine (MGT). A $1 \mathrm{MW}$ scale of solar farm was first designed according to IEC 60364-552:2003, MS281837 and AMBO Chart method. Then, designed solar farm and MGT were modelled and simulated Simulink. In this study, both system need to stabilize power output at $800 \mathrm{~kW}$ throughout the year. It was found that it is possible to balance the power output of the solar farm to have constant power output throughout the year at $800 \mathrm{~kW}$. However, all MGTs frequently operated at partial load that decreased their efficiency. Thus, it is possible to solve the solar farm problem with the technique, but further investigation the environmental and economic impact in comparison with a conventional power generation and a solar farm only is needed.
\end{abstract}

\section{Introduction}

Photovoltaic (PV) in large-scale as solar farm is significantly increasing in recent years. However, solar farm at high portion of the whole grid demand causes concerns in keeping supply-and-demand balance because of power fluctuations nature of PV. This is called as "Duck Curve" by California Independent System Operator (CAISO). The duck curve illustrates two areas of concern, first is the possibility of excess generation in day time due to the inability of the grid to integrate large amount of solar generation. The second area of

\footnotetext{
*Corresponding author: mfirdausb@ump.edu.my
} 
concern is the need for the grid to ramp up quickly enough to meet the evening peak where the solar is not available.

Smoothing solar farm output found to be an economical method. Effects like voltage fluctuation, reverse power flow and frequency deviation produced due to PV power output fluctuations can be reduced by complementing PV with rapid energy storage technologies such as batteries, fuel cell, capacitors with more effective control [1,2].

On the other hand, a hybrid renewable energy generation system that combines more than one energy sources working together for electrical services could also reduce the severeness of this problem [3-5].

In addition, it is also possible to control the output total of PVs at the point of generation before being supply to grid. Thus, the grid operator does not have any issue on stabilizing the grid if solar farm could control it output. This, is possible if the solar farm is integrated with reliable and stable power generation that could supply the amount of power that is needed by the grid. Micro Gas Turbine (MGT) could be one of the options because of its capability to follow the demand, low NOx emission and well commercialized prime mover. However, there is no study on the stabilizing power output of large scale PV as solar farm by integrating the solar farm with MGT.

Thus, the objective of this paper is to analyze the performance of MGT integrated Solar Farm. The whole $1 \mathrm{MW}$ Solar farm with inverter was designed and simulated, and then MGT also simultaneously operated to ensure amount of power injected to the grid is constant throughout the simulation period.

\section{Materials and methods}

\subsection{Grid connected PV design and sizing}

The PV modules were $315 \mathrm{kWp}$ monocrystalline SPR-315E-WHT-D, and the central inverter was PVS800 $1000 \mathrm{~kW}$. PVs and the inverter were selected and matched by AMBO Chart method. Lastly the BOS components for the system were sized based on IEC 603645-52:2003 and MS281837. The solar farm has 3,080 modules and producing a total of 970 $\mathrm{kW}$ at STC. After the whole solar farm design was completed, all component were modelled in Simulink for a simulation. The specification of the PV and the inverter are shown in Table 1 and Table 2.

Table 1. PV module specification

\begin{tabular}{|l|l|l|l|}
\hline \multicolumn{1}{|c|}{ Parameter } & \multicolumn{1}{|c|}{ Value } & \multicolumn{1}{c|}{ Parameter } & \multicolumn{1}{c|}{ Value } \\
\hline Peak power (Pmax) & $315 \mathrm{~W}$ & Short circuit current (Isc) & 6.14 \\
\hline Rated voltage (Vmpp) & $54.7 \mathrm{~V}$ & NOCT & $45^{\circ} \mathrm{C}+/-2{ }^{\circ} \mathrm{C}$ \\
\hline Rated current (Impp) & $5.76 \mathrm{~A}$ & Length $($ L) & $1064 \mathrm{~mm}$ \\
\hline Open circuit voltage (Voc) & $64.6 \mathrm{~V}$ & Width $(W)$ & $1559 \mathrm{~mm}$ \\
\hline
\end{tabular}

Table 2. Specification of the choosen inverter

\begin{tabular}{|l|l|l|l|}
\hline \multicolumn{1}{|c|}{ Parameter } & \multicolumn{1}{|c|}{ Value } & \multicolumn{1}{c|}{ Parameter } & \multicolumn{1}{c|}{ Value } \\
\hline Type designation & PVS800-57- & Maximum DC current $\left(I_{\max }(D C)\right.$ & $1,710 \mathrm{~A}$ \\
& $1,000 \mathrm{~kW}-\mathrm{C}$ & & \\
\hline DC voltage range, $\mathrm{mpp}\left(U_{D C, m p p}\right)$ & 600 to $850 \mathrm{~V}$ & Number of protected DC inputs & 8 to $20(+/-)$ \\
\hline
\end{tabular}




\begin{tabular}{|l|l|l|l|}
\hline Maximum DC voltage $\left(U_{\max }(D C)\right.$ & $1,100 \mathrm{~V}$ & Efficiency & $98.8 \%$ \\
\hline
\end{tabular}

\subsection{PV system model}

The mathematical model of PV module in Simulink was developed based on the method proposed by [20] and [21]. As shown in Fig. 1 the model basically requires two inputs which are the $T_{a m b}$ and $\bar{I}_{G}$. Based on the hourly inputs, the model will calculate the amount of energy generated by the PV module, $E_{P V}[\mathrm{kWh}]$ as the output in that hour.

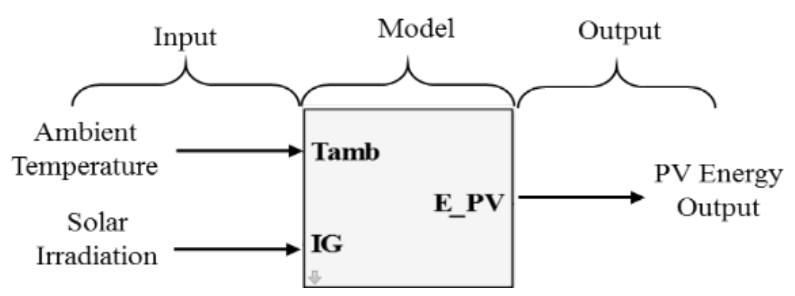

Fig. 1. PV model in simulink

$E_{P V}$ is calculated by Eq. (1) where $P_{P V}$ is the rated power output of a single PV module [kW], $K_{G}$ is the coefficient of solar irradiation [-], $K_{T}$ is the coefficient of module temperature [-], $K_{\text {dirt }}$ is the coefficient of loses due to dirt or dust on the PV module surface [-], $K_{\text {mismatch }}$ is the coefficient of loses due to interconnection of PV modules that do not have identical properties [-], and $N_{M}$ is the number of module available in the hybrid system.

$$
E_{P V}=P_{P V} \times K_{G} \times K_{T} \times K_{\text {Dirt }} \times K_{\text {mismatch }} \times N_{M}
$$

$K_{G}$ can be calculated by Eq. (2).

$$
K_{G}=\frac{\bar{I}_{G}}{\bar{I}_{G . S T C}}
$$

where $\bar{I}_{G}$ is the hourly global solar irradiation of the demand site $\left[\mathrm{kW} / \mathrm{m}^{2}\right]$ and $\bar{I}_{G . S T C}$ is the global solar irradiation at STC. $K_{T}$ can be calculated from the expression given in Eq. (3).

$$
K_{T}=\left[1+\left(\frac{\beta}{100}\right) \times\left(T_{C}-T_{S T C}\right)\right]
$$

where the $\beta$ is the temperature coefficient given by manufacture in $\left[\% /{ }^{\circ} \mathrm{C}\right], T_{C}$ is PV module cell temperature $\left[{ }^{\circ} \mathrm{C}\right]$, and $T_{S T C}$ is PV module cell temperature at STC $\left[{ }^{\circ} \mathrm{C}\right]$. The $T_{C}$ of the PV module can be estimated using Eq. (4).

$$
T_{C}=\frac{N O C T}{800} \times \bar{I}_{G}-T_{a m b}
$$

where NOCT is the nominal operating cell temperature of the PV module $\left[{ }^{\circ} \mathrm{C}\right]$. Finally, once the hourly $E_{P V}$ was calculated, the hourly efficiency of the PV module can be estimated by Eq. (5). 


$$
\eta_{P V}=\frac{E_{P V}}{A_{P V} \times N_{M} \times \bar{I}_{G}}
$$

where $A_{P V}$ is the area of a single PV module $\left[\mathrm{m}^{2}\right]$.

\subsection{MGT system model}

5 unit of $200 \mathrm{~kW}$ MGT model was adopted for the simulation. The model is extensively elaborated in previous literature $[6,7]$. The basic performance are reported at ISO conditions is shown in Table 3. At the rated power output, the electrical efficiency is $33 \%$.

Table 3. Summary of nominal performance at full load power and ISO conditions for MGT

\begin{tabular}{|l|l|}
\hline \multicolumn{1}{|c|}{ Parameter } & \multicolumn{1}{c|}{ Value } \\
\hline Net power output & $200(+0 /-4) \mathrm{kW}$ \\
\hline Net efficiency (LHV) & $33(+-2) \%$ \\
\hline Nominal steady fuel flow (HHV) & $2400000 \mathrm{~kJ} / \mathrm{hr}$ \\
\hline
\end{tabular}

Fig. 2 illustrates the MGT model block developed in the Simulink environment. As shown in Fig. 2, the inputs of the model are $T_{a m b}$ and $L F$, whereas the output of the model are Power and Exhaust heat output that finally became Energy Output, mass flow rate of exhaust gas and its temperature, and fuel consumption.

MGTs will operate one by one until the whole MGT integrated solar farm could generate $800 \mathrm{~kW}$ of power output. Only MGTs generates $800 \mathrm{~kW}$ at night, whereas MGTs only generate the portion that solar farm could not generate to achieve $800 \mathrm{~kW}$ during day time

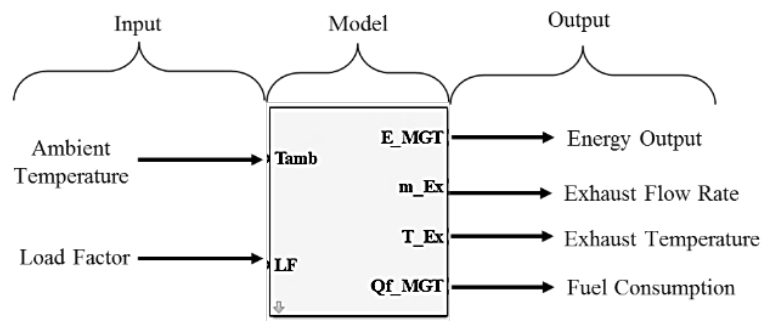

Fig. 2. PV model in simulink.

\section{Results and discussion}

\subsection{Power output stabilization}

Fig. 3 shows the results of the MGT integrated solar farm for 3 days. Green line shows the power output of the solar farm, red line shows the total power output of the multiple MGT, and the black line shows the sum of power output from former and later. It was found that MGTs operate most of the time and it power generation reduced during day time. This is when PV could generate electricity especially during afternoon. By this strategy, it was found that the total power output at the solar farm could be maintained at $800 \mathrm{~kW}$.

Fig. 4 shows the hourly efficiency of the solar farm throughout the year. It was found that the average power generation efficiency of the solar farm was $13.78 \%$ at peak hour.

Fig. 5 shows the efficiency of all MGTs throughout the year. Since MGTs need to balance the power output of solar farm to achieve $800 \mathrm{~kW}$, they operate at lower partial load 
and efficiency also decreased. MGT1 has high efficiency throughout the year because it is the first MGT that operates to balance the solar farm output. Whereas, MGT5 has the lowest efficiency because it is the last MGT to operate and therefore always operate at lower partial load. Thus, it is possible to have MGT integrated solar farm with controllable power output that could solve the problem of power output fluctuation and imbalance between supplydemand in grid system by the solar farm. However, further investigation on the environmental and economic impact in comparison with a conventional power generation and a solar farm only is needed.

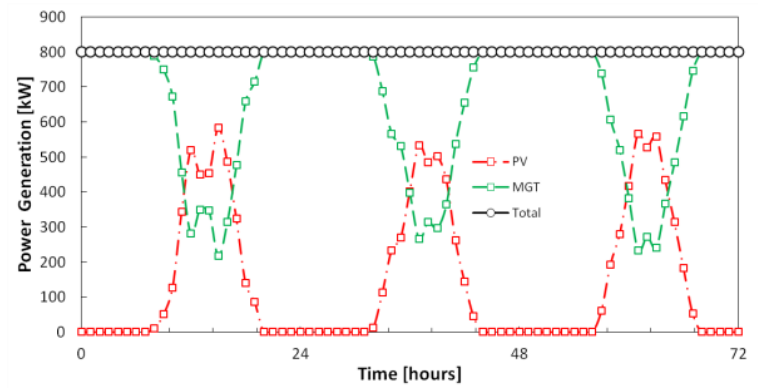

Fig. 3. Power output of MGT integrated solar farm

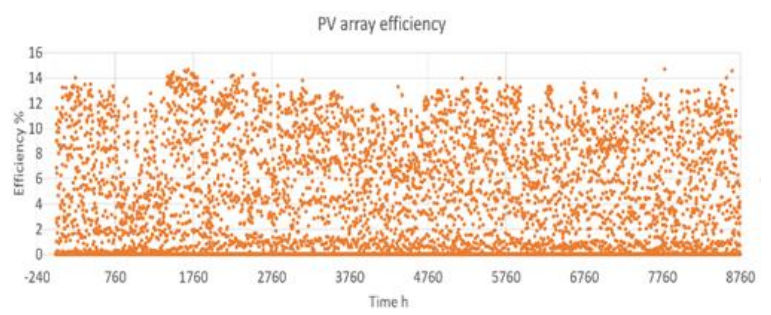

Fig. 4. Power generation efficiency of the solar farm
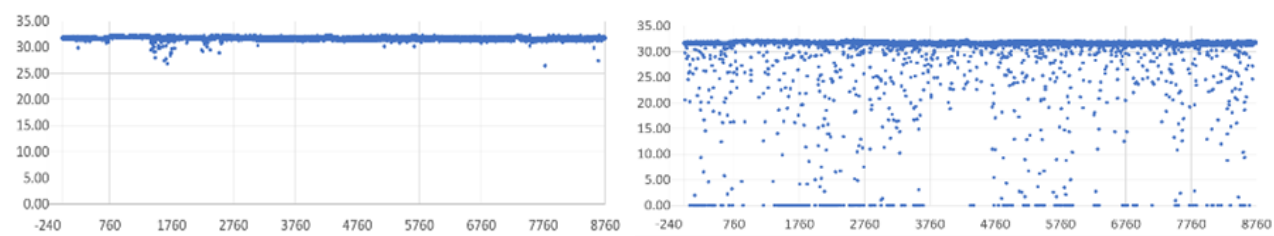

(a) MGT1

(b) MGT2
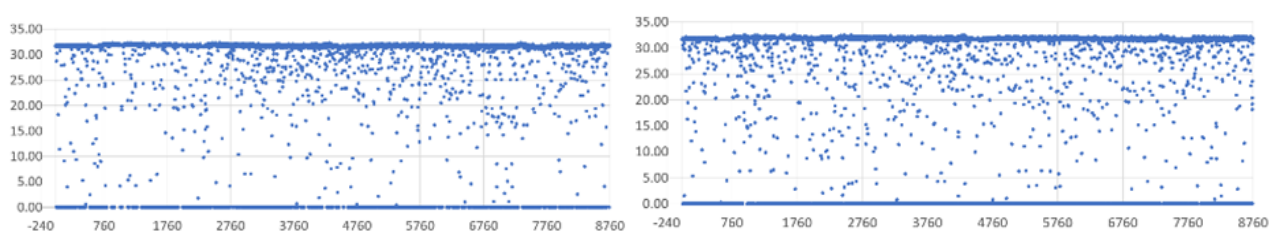

(c) MGT3

(d) MGT4 


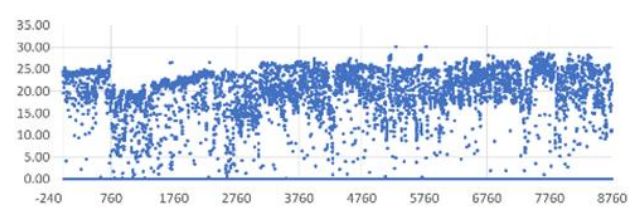

(e) MGT5

Fig.5. Efficiency of all MGTs throughout the year

\section{Conclusion}

Multiple unit of MGTs were integrated in a solar farm to solve the problem of power output fluctuation and imbalance between supply-demand in grid system by the solar farm. $970 \mathrm{~kW}$ scale of solar farm was designed and modelled, and then MGTs were modelled and integrated with the solar farm. Simulation in simulink shows that it is possible to balance the power output of the solar farm to have constant power output at $800 \mathrm{~kW}$ throughout the year. However, all MGTs frequently operated at partial load that decreased their efficiency. Thus, it is possible to solve the solar farm problem with the technique, but further investigation the environmental and economic impact in comparison with a conventional power generation and a solar farm only is needed.

The financial support offered by the Universiti Malaysia Pahang under RDU RDU180313 are gratefully acknowledged

\section{References}

1. A. Choudar, D. Boukhetala, S. Barkat, and J.-M. Brucker, Ene Conv and Manage, 90, 21-33, (2015).

2. S. Y. Kan, M. Verwaal, and H. Broekhuizen, J of Pow Sources, 162, 971-974, (2006).

3. T. Capuder and P. Mancarella, Ene, vol. 71, 516-533, (2014).

4. X. Li, Y. Li, X. Han, and D. Hui, Energy Procedia, 12, 994-1001, (2011).

5. W. Wu, V. I. Christiana, S.-A. Chen, and J.-J. Hwang, Ene, 84, 462-472, (2015).

6. F. Basrawi, T. K. Ibrahim, K. Habib, T. Yamada, and D. M. N. Daing Idris, Ene, 124, 238-248, (2017).

7. F. Basrawi, T. Yamada, and K. Nakanishi, Heat Transfer-Asi Res, 42, 556-568, (2013). 